Tropical Journal of Pharmaceutical Research April 2018; 17 (4): 597-603

ISSN: $1596-5996$ (print); 1596-9827 (electronic)

(C) Pharmacotherapy Group, Faculty of Pharmacy, University of Benin, Benin City, 300001 Nigeria.

\title{
$\beta$-Elemene alleviates bone cancer-related pain in rats by modulating N-methyl-D-aspartate receptor 2B subunit
}

\author{
Liyan Gong ${ }^{1}$, Hu Cai ${ }^{2 \star}$, Qinfei Zhou ${ }^{1}$, Xiangming Kong ${ }^{1}$ \\ ${ }^{1}$ Comperehensive Medical Oncology, Zhejiang Cancer Hospital, ${ }^{2}$ Department of Integrated Traditional Chinese Medicine and \\ Western Medicine, Zhejiang Cancer Hospital, Zhejiang 310022, China
}

*For correspondence: Email: caihucah79@163.com

Sent for review: 5 January 2018

Revised accepted: 27 March 2018

\begin{abstract}
Purpose: To investigate the effect of $\beta$-elemene on bone cancer-related pain (BCRP) and its underlying mechanism in a rat model.

Methods: A rat model of BCRP was established by injection of Walker 256 cells into the medullary cavity in adult male Sprague-Dawley rats. The effects of $\beta$-elemene on pain-related behaviours were assessed by paw withdrawal mechanical threshold (PWMT) and paw withdrawal thermal latency (PWTL). Quantitative real-time polymerase chain reaction (qRT-PCR) and western blotting were used to analyse the transcription and translation levels of $N$-methyl-D-aspartate receptor $2 B$ subunit (NR2B), respectively.

Results: This study found that PWMT and PWTL were significantly decreased in rats as evidence of successful establishment of a rat model of BCRP. Behavioral test showed that $\beta$-elemene treatment could attenuate pain-related behaviours. This analgesic effect began $1 \mathrm{~h}$ after drug injection, reached the highest value at $2 h$, declined at $4 h$, and disappeared by $24 h$. qRT-PCR and western blotting indicated that intrathecal administration of $\beta$-elemene down-regulated mRNA and protein levels of NR2B.

Conclusion: The results show that $\beta$-elemene alleviates behaviours related to pain in a rat model of $B C R P$ probably by modulating NR2B, thus indicating a new potential treatment method for cancerrelated pain.
\end{abstract}

Keywords: $\beta$-Elemene, Bone cancer, Pain relief, N-methyl-D-aspartate receptor 2B subunit (NR2B), Sensitisation

\begin{abstract}
This is an Open Access article that uses a funding model which does not charge readers or their institutions for access and distributed under the terms of the Creative Commons Attribution License (http://creativecommons.org/licenses/by/4.0) and the Budapest Open Access Initiative (http://www.budapestopenaccessinitiative.org/read), which permit unrestricted use, distribution, and reproduction in any medium, provided the original work is properly credited.
\end{abstract}

Tropical Journal of Pharmaceutical Research is indexed by Science Citation Index (SciSearch), Scopus, International Pharmaceutical Abstract, Chemical Abstracts, Embase, Index Copernicus, EBSCO, African Index Medicus, JournalSeek, Journal Citation Reports/Science Edition, Directory of Open Access Journals (DOAJ), African Journal Online, Bioline International, Open-J-Gate and Pharmacy Abstracts

\section{INTRODUCTION}

Bone cancer-related pain (BCRP) is one of the common type of pain in malignant tumour patients [1]. Cancers with strong predilection to metastasize to bone, such as breast and prostate carcinoma, are the main causes of malignant bone disease $[2,3]$. The pain caused by bone cancer significantly decreases the quality of life of patients. Despite decades of basic and clinical research on BCRP, the exact molecular mechanisms and effective therapies for BCRP are still challenging problems [4]. Current treatments for BCRP are not sufficiently effective or can cause significant adverse effects [5]. 
$\beta$-Elemene is a natural product found in about 50 plants used for herbal medicine that grow in tropical areas [6]. $\beta$-Elemene was reported to repress DNA synthesis and the proliferation of cancer cells in a broad range of tumours, including breast, bladder, and prostate cancers, without severe side effects [6-9]. However, the efficacy of $\beta$-elemene as a BCRP treatment is unknown, and the mechanism involved in the relief of BCRP by $\beta$-elemene remains to be determined. N-methyl-D-aspartate (NMDA) receptors are relevant to chronic neuropathic pain, injury-induced pain behaviour and persistent pain of spinal lamina II neurons [1013]. The NMDA receptor $2 B$ subunit $\left(N_{R} 2 B\right)$ shows a relatively restricted distribution in pathways of nociceptive transmission [14]. Previous studies suggest that BCRP can be attenuated by modulation of $\mathrm{N}_{\mathrm{R}} 2 \mathrm{~B}$ by masrelated gene $C$ activation [15]. Furthermore, $\mathrm{N}_{\mathrm{R}} 2 \mathrm{~B}$ in spinal cord plays a part role in inflammatory and neuropathic pain $[16,17]$.

The aim of this research was to investigate the effects of $\beta$-elemene on pain-related behaviours and $\mathrm{N}_{\mathrm{R}} 2 \mathrm{~B}$ expression in a rat model of $\mathrm{BCRP}$, and thus a new potential therapy for BCRP were investigated.

\section{EXPERIMENTAL}

\section{Experimental animals}

Adult male Sprague-Dawley rats (body weight ranges from $230 \mathrm{~g}$ to $260 \mathrm{~g}$ ) were housed in cages in groups of five and kept under a half day light/ $12 \mathrm{~h}$ dark cycle at $24{ }^{\circ} \mathrm{C}$ with food and water supplied ad libitum. These rat experiments in this study were approved by Zhejiang Cancer Hospital and in accordance with the Guidelines of the International Association for the Study of Pain [18]. Efforts were made to reduce the numbers of rats and the pain they experienced in the work.

\section{Establishment of rat model of BCRP}

Walker 256 rat mammary carcinoma cells used for implantation were grown in RPMI-1640 medium (San Diego, USA) in an incubator with 5 $\% \mathrm{CO}_{2}$ at $37^{\circ} \mathrm{C}$. The medium also comprised $100 \mathrm{U} / \mathrm{mL}$ penicillin, $0.1 \mathrm{mg} / \mathrm{mL}$ streptomycin and $15 \%$ fetal bovine serum (Biomiga, Inc.). A rat model of BCRP was established following the protocol reported by Schwei et al. with slight modification [19]. Anaesthetization of rats was performed by injecting pentobarbital sodium (1\% in saline) at $50 \mathrm{mg} / \mathrm{kg}$. After shaving the rats and disinfecting with $70 \%(\mathrm{v} / \mathrm{v})$ ethanol, an incision was made on the right articulation genu.
Perforation of the tibial plateau was performed by gauge needle. The injection of $10 \mu \mathrm{L}$ of medium or Walker 256 cells $\left(5 \times 10^{5}\right.$ cells $)$ into the medullary cavity of the rats in the normal control or tumour groups was performed by microsyringe (Hamilton, USA). The hole of injection was sealed by bone wax, and Gentamicin saline was used to wash the wound before closure.

\section{Drug injection and grouping}

To determine whether $\beta$-elemene alleviates painrelated behaviours, rats were injected with $\beta$ elemene followed by testing of nociceptive behaviours. $\beta$-Elemene used in this study was purchased from Yuanda Pharmaceuticals (Dalian, China). It was dissolved in dimethyl sulfoxide (DMSO) at $0.1 \%$ and diluted by physiological saline. On day 14 after modeling, $\beta$-elemene was given intratibially at $40 \mathrm{mg} / \mathrm{kg}$ in tumor $+\beta$-elemene group, and equal amount of DMSO and physiological solution was given intratibially in tumor + vehicle group and normal control + vehicle group. Rat were devided into the following three groups (1) tumor $+\beta$-elemene group: (rats with BCRP model received intratibial injection of $\beta$-elemene); (2) tumor + vehicle group (rats with BCRP model treated by intratibial injection of equal amount of DMSO and physiological saline); (3) normal control + vehicle group (normal rats treated by intratibial injection of equal amount of DMSO and physiological saline).

\section{Behavioral test}

Before the measurements were performed, all rats acclimatized to the new environment for 30 min before tests. Mechanical allodynia was evaluated by paw withdrawal mechanical threshold (PWMT), which referred to the lowest force (in grams) causing mechanical withdrawal. Rats were kept in a glass chamber with mesh floor. The mechanical allodynia was generated by filaments in a sequentially increasing strength order, vertically against the paw to lead to paw bending for $5 \mathrm{~s}$ using a series of von Frey hairs (Stoelting, USA). Thermal hyperalgesia was measured by paw withdrawal thermal latency (PWTL). The animal was kept in glass chamber with a transparent bottom. Radiant heat apparatus (IITC Life Science) was placed underneath the bottom and focused onto the paw through the transparent bottom. PWTL represented the time of heat stimulation leading to the withdrawal of the paws. A cut-off period of $20 \mathrm{~s}$ was set to decrease empyrosis caused by radiant heat. PWMT and PWTL were examined before animal modeling, after animal modeling and after drug administration. 


\section{Western blotting analysis}

Before western blotting analysis, the rats were anesthetized by isoflurane and then sacrificed by cervical dislocation. Protease and phosphatase inhibitor were used to homogenize the samples from the tissue in spinal cord L4-L6 segment. After centrifugation at $13000 \mathrm{rpm}$ for $8 \mathrm{~min}$ at 4 ${ }^{\circ} \mathrm{C}$, the resultant supernatant was analysed by BCA Protein Assay Kit (JiebeisiBiotec, Guangzhou, China) for further analysis. The samples were boiled loading buffer for $10 \mathrm{~min}$. After centrifugation, protein sample in the resultant supernatant was separated by $10 \%$ SDS-PAGE using electrophoresis. After separation by electrophoresis, the proteins on the gel were transferred to PVDF membrane (Millipore, USA). After blocked by skim milk for 2 h at $24^{\circ} \mathrm{C}$, the membrane was treated by the first antibody rabbit- $\mathrm{N}_{\mathrm{R}} 2 \mathrm{~B}(1: 1000)$. The membrane was washed by TBST buffer (containing $10 \mathrm{mM}$ Tris- $\mathrm{HCl}, \mathrm{pH} 8,150 \mathrm{mM} \mathrm{NaCl}$ and $0.05 \%(\mathrm{v} / \mathrm{v})$ Tween 20). Then the membrane was treated by second goat-rabbit antibody with horseradish peroxidase (1:5000) for $120 \mathrm{~min}$ at $24{ }^{\circ} \mathrm{C}$.

The bands were tested using the ECL system (Millipore, USA). The results were analysed using QuantityOne V4.40 (Bio-Rad, CA, USA), with $\beta$-actin $(1: 1000)$ as reference. All the antibodies were purchased from Abcam (UK). Western blotting analysis was performed before animal modeling, after animal modeling and after drug administration.

\section{Quantitative real-time polymerase chain reaction (qRT-PCR)}

Before western blotting analysis, the rats were anesthetized by isoflurane and then sacrificed by cervical dislocation. The samples from the tissue of spinal cord L4-L6 segment were used for RNA extraction with Trizol Reagent (Invitrogen, USA). The concentration of RNA was analysed by Nanodrop 2000 (Thermo Fisher, USA). PrimeScrip RT reagent kit (Takara Biomedical Technology, China) was employed in reverse transcription. qRT-PCR was analysed by SYBR Fast qPCR Mix (Takara Biomedical Technology, China) on Real-time PCR System (Applied Biosystems, USA) in triplicates.

The primers of $\mathrm{N}_{\mathrm{R}} 2 \mathrm{~B}$ and $\beta$-actin used for qRTPCR were listed in Table 1 [20]. The relative expression level of $\mathrm{N}_{R} 2 \mathrm{~B}$ was calculated by compared with that of $\beta$-actin using CT method [21]. qRT-PCR was performed before animal modeling, after animal modeling and after drug administration.
Table 1: Primers for qRT-PCR

\begin{tabular}{lll}
\hline Gene & Forward/Reverse & $\begin{array}{l}\text { Primer } \\
\text { sequence }\end{array}$ \\
\hline $\mathbf{N}_{\mathbf{R}}$ 2B & Forward & $\begin{array}{l}\text { GCATTCCTAC } \\
\text { GACACCTTCG }\end{array}$ \\
\cline { 2 - 3 } & Reverse & $\begin{array}{l}\text { GACCACCACT } \\
\text { GGCTTATTGG }\end{array}$ \\
\hline $\boldsymbol{\beta}$ Actin & Forward & GAGACCTTCA \\
\cline { 2 - 3 } & Reverse & ACACCCCAGC \\
\hline & & CACAGAGTAC \\
& & TTGCGCTCAG \\
\hline
\end{tabular}

\section{Statistical analysis}

The data in this study are presented as mean \pm standard deviation (SD). Rats were divided into normal control and tumour groups randomly. Variance analysis between two groups were analysed by Student's $t$-test. Variance analysis between more than two groups were analysed by one-way ANOVA followed by Tukey's post hoc tests. SPSS 16.0 was used for statistical analysis. $p<0.05$ was used to define statistical significance.

\section{RESULTS}

\section{Analysis of BCRP-related behaviour}

Before model establishment (day 0), PWMT (Figure 1A) and PWTL (Figure 1B) were equivalent between rats in the normal control and tumour groups. After operation, rats in both groups showed reduced PWMT and PWTL on day 3. From day 5 to 14, PWMT and PWTL were increased in the normal control group and showed no significant differences when compared with values on day 0 . The tumour group showed slightly higher PWMT and PWTL on day 5 than on day $3(p>0.05)$. However, from day 5 onward, PWMT and PWTL declined gradually in the tumour group. On days 7, 10, and 14, PWMT and PWTL were obviously lower in the tumour group than those in the normal control group $(p<0.05)$.
A

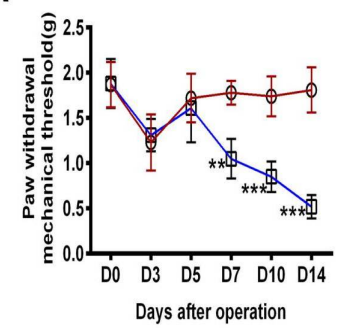

B

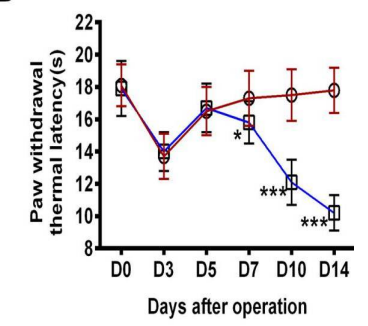

Figure 1: Behavioural testing of a rat model of BCRP. (A) PWMT in normal control and tumour groups at different time points. (B) PWTL in normal control and 
tumour groups at different time points. Day 0 was before the operation, whereas days $3,5,7,10$, and 14 were after the operation. $\circ=$ normal control; $\mathbf{0}=$ tumour groups; * $p<0.05,{ }^{* *} p<0.01,{ }^{* * *} p<0.001$ vs. normal control group

\section{Transcription and expression of $\mathrm{N}_{\mathrm{R}} 2 \mathrm{~B}$}

After model establishment, mRNA levels of $\mathrm{N}_{\mathrm{R}} 2 \mathrm{~B}$ in the normal control group were markedly lower compared to those in the tumour group on days $3,5,7,10$, and $14(p<0.05$; Figure $2 \mathrm{~A})$ and increased over time. Western blotting indicated that on day 3 after model establishment, the protein expression levels of $\mathrm{N}_{\mathrm{R}} 2 \mathrm{~B}$ in the tumour group showed no obvious changes in comparison with those of normal control group (Figure 2B). Nevertheless, on days 5, 7, 10, and 14 , the translation of $N_{R} 2 B$ in tumour group was markedly up-regulated in a time-dependent manner.

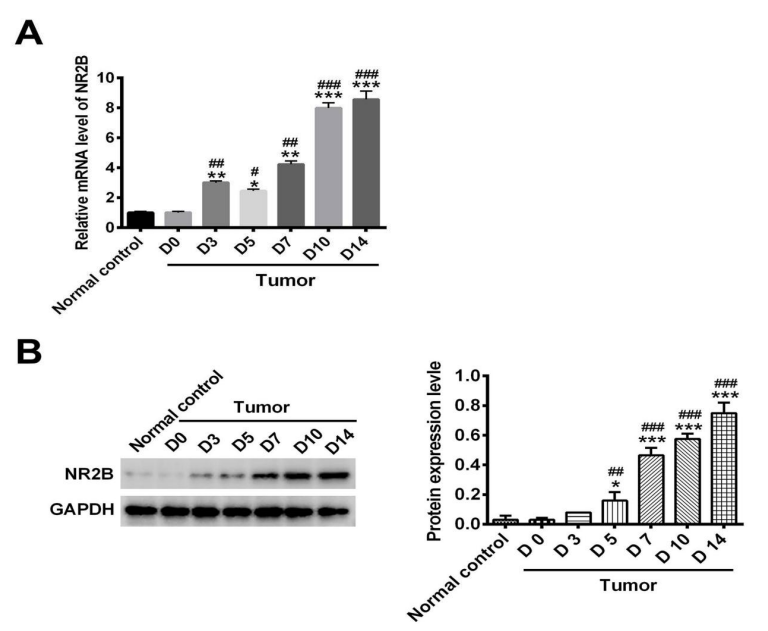

Figure 2: Relative expression levels of $N_{R} 2 B$ in a rat model of BCRP. (A) Relative mRNA level of $N_{R} 2 B$. (B) Protein bands of $\mathrm{N}_{\mathrm{R}} 2 \mathrm{~B}$ and $\beta$-actin; ${ }^{*} p<0.05$, ${ }^{* *} p<$ $0.01,{ }^{* * *} p<0.001$ vs normal control group; $\# p<0.05$, $\# \# p<0.01, \# \# \#<<0.001$ vs. tumour group

\section{Effects of $\beta$-elemene on mechanical allodynia and thermal hyperalgesia}

The tumour + vehicle group had a markedly lower PWMT than the normal control + vehicle group $(p<0.05$; Figure 3A). However, the tumour $+\beta$-elemene group had a higher PWMT than the tumour + vehicle group $(p<0.05)$ and a similar PWMT as the normal control + vehicle group at 2, 4, 6, and $12 \mathrm{~h}$ after drug administration. At $24 \mathrm{~h}$ after drug administration, PWMT in the tumour + $\beta$-elemene group decreased and showed no significant difference from that in the tumour + vehicle group. PWTL showed similar variations between the two groups (Figure 3B). Thus, the analgesic effect of $\beta$-elemene showed to begin $2 \mathrm{~h}$ after drug administration, reached maximal levels at $4 \mathrm{~h}$, decreased at $6 \mathrm{~h}$, and disappeared by $24 \mathrm{~h}$.
A

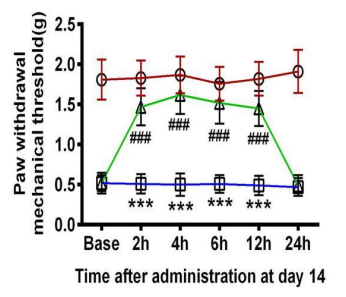

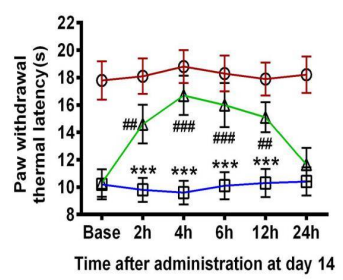

Figure 3: Changes in pain-related behaviours in response to $\beta$-elemene treatment. (A) PWMT in normal control + vehicle group, tumour + vehicle group, and tumour $+\beta$-elemene group. (B) PWTL in normal control + vehicle group, tumour + vehicle group, and tumour $+\beta$-elemene group. Baseline values were obtained before injection. \#\#\# $p>0.05$, $\# \# p<0.05$ vs. normal control + vehicle group; $\circ=$ normal control + vehicle group; $\mathbf{a}=$ tumour + vehicle group; $\Delta=$ tumour $+\beta$-elemene group; ${ }^{* \star *} p<0.001$ vs. tumour + vehicle group

Effects of $\beta$-elemeneon transcription and expression of $\mathrm{N}_{\mathrm{R}} 2 \mathrm{~B}$

At baseline, the mRNA level of $\mathrm{N}_{\mathrm{R}} 2 \mathrm{~B}$ in tumour + vehicle group was greater compared to that in normal control + vehicle group (Figure 4A). However, at 1,2 , and $4 \mathrm{~h}$ after $\beta$-elemene injection, the mRNA level of $N_{R} 2 B$ in tumour $+\beta$ elemene group was less in comparison with that in tumour + vehicle group but greater compared with that in normal control + vehicle group $(p<$ 0.05 ). At $24 \mathrm{~h}$ after $\beta$-elemene injection, the difference between the tumour $+\beta$-elemene and tumour + vehicle groups disappeared $(p>0.05)$. The protein level of $N_{R} 2 B$ in the tumour $+\beta$ elemene group was down-regulated in a timedependent manner than that in tumour + vehicle group. Thus, effects of $\beta$-elemene on $\mathrm{N}_{\mathrm{R}} 2 \mathrm{~B}$ protein expression began at $2 \mathrm{~h}$ after drug administration, reached maximal levels at $6 \mathrm{~h}$, and decreased at 12 and $24 \mathrm{~h}$. Therefore, the protein level of $\mathrm{N}_{R} 2 \mathrm{~B}$ in the tumour $+\beta$-elemene group was still higher compared with that in normal control + vehicle group, even though it was down-regulated by $\beta$-elemene.

\section{Effect of $\beta$-elemene on histomorphometry}

Compared with the normal control + vehicle group, the cancer + vehicle and cancer $+\beta-$ elemene groups showed thinner and irregular bone trabeculae and destroyed bone trabecular reticulate structures (Figure 5). Thus, $\beta$-elemene treatment did not improve bone trabecular distribution. 
A

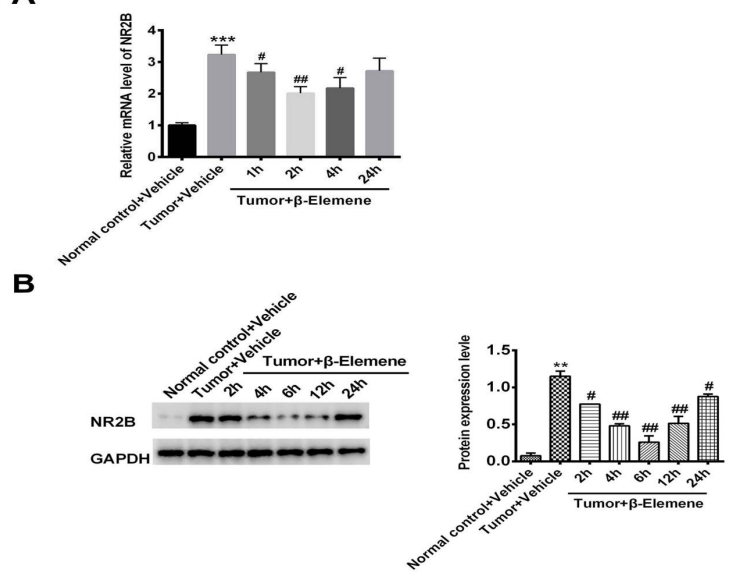

Figure 4: Relative expression level of $N_{R} 2 B$ after $\beta$ elemene administration. (A) Relative mRNA level of $\mathrm{N}_{\mathrm{R}} 2 \mathrm{~B}$. (B) Protein bands for $\mathrm{N}_{\mathrm{R}} 2 \mathrm{~B}$ and GAPDH; ${ }^{* *} p<$ 0.01 vs. normal control + vehicle group; \# $p<0.05$, \#\# $p<0.01$ vs. tumour + vehicle group

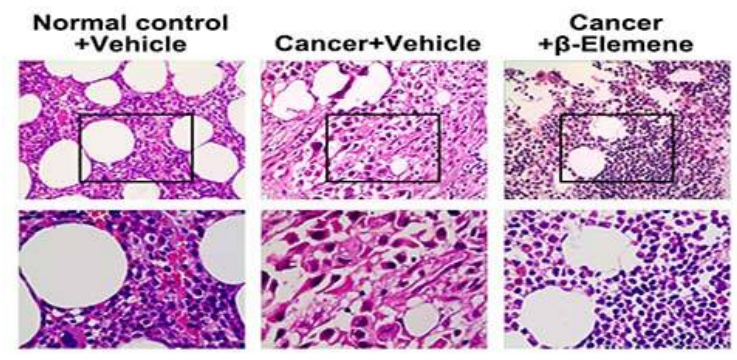

Figure 5: Histological analysis of bone trabeculae in response to $\beta$-elemene treatment

\section{DISCUSSION}

BCRP, which strongly affects the quality of life of cancer patients, can be evaluated by mechanical and thermal hyperalgesia, which involve sensitisation in the spinal cord [22]. NMDA receptor-dependent central sensitisation was accounting for pain hypersensitivity [23]. In particular, the activation of $\mathrm{N}_{\mathrm{R}} 2 \mathrm{~B}$ was necessary for the formation of central sensitisation [24].

The present study found that PWMT and PWTL decreased in normal control and tumour groups on day 3 after operation due to effects of the operation, as both groups of rats showed recovered behaviour on day 5 . On day 14, PWMT and PWTL of normal control groups recovered to basal values, whereas the tumour group showed significantly decreased PWMT and PWTL when compared with basal values before model establishment. Thus, the decreased PWMT and PWTL appeared to be caused by BCRP. These results indicate that a BCRP model was successfully established in rats and that BCRP-related behaviours tended to stabilise 14 days after operation.
The results of qRT-PCR and western blotting indicated that transcription and translation of $\mathrm{N}_{\mathrm{R}}$ 2B in spinal cord were markedly elevated after model establishment. The increased mRNA and protein levels of $\mathrm{N}_{\mathrm{R}} 2 \mathrm{~B}$, which were accompanied by BCRP-related behaviours, suggest that $\mathrm{N}_{R} 2 \mathrm{~B}$ is related to the development of BCRP. This is consistent with previous results from qRT-PCR and immunohistochemical staining [25].

In the present study, PWMT and PWTL decreased after drug administration, indicating that $\beta$-elemene can alleviate both mechanical and thermal hyperalgesia in a rat model of BCRP. Behavioural tests showed that the analgesic effect of $\beta$-elemene reached its maximal level $4 \mathrm{~h}$ after drug administration, decreased at $6 \mathrm{~h}$, and disappeared by $24 \mathrm{~h}$. Therefore, although $\beta$-elemene may quickly alleviate pain, the effect does not persist for long. Intrathecal administration of $\beta$-elemene downregulated mRNA and protein levels of $N_{R} 2 B$, corresponding with pain-related behavioural changes. Tan et al. also found that gene knockdown of $\mathrm{N}_{\mathrm{R}} 2 \mathrm{~B}$ by siRNA reduces formalininduced nociception [26].

$\mathrm{Qu}$ et al showed that the $\mathrm{N}_{\mathrm{R}} 2 \mathrm{~B}$ receptor antagonist ifenprodil inhibits mechanical allodynia [27]. Gu et al reported that $\mathrm{N}_{\mathrm{R}} 2 \mathrm{~B}$ might play a role in BCRP in mice, as intrathecal administration of $\mathrm{N}_{\mathrm{R}} 2 \mathrm{~B}$ receptor antagonist reduces thermal hyperalgesia and mechanical allodynia [25]. In the present study, $\beta$-elemene probably regulated pain-related behaviours by targeting $\mathrm{N}_{\mathrm{R}} 2 \mathrm{~B}$ at the transcriptional level, both mRNA and protein levels of $\mathrm{N}_{\mathrm{R}} 2 \mathrm{~B}$ were decreased by $\beta$-elemene in a rat model of BCRP.

\section{CONCLUSION}

These results show that $\beta$-elemene alleviates thermal hyperalgesia and mechanical hyperalgesia in a rat model of BCRP by modulating $\mathrm{N}_{\mathrm{R}} 2 \mathrm{~B}$, and thus presenting a new potential therapy for BCRP.

\section{DECLARATIONS}

\section{Acknowledgement}

This work was supported by grants from Zhejiang Provincial Medical and Health Scientific and Technical Fund (no. 2015KYB066), Zhejiang Provincial Medical and Health Scientific and Technical Fund (no. 2018KY312) and Zhejiang Provincial Traditional Chinese Medicine Fund (no. 2016ZB027). 


\section{Conflict of interest}

No conflict of interest is associated with this work.

\section{Contribution of authors}

We declare that this work was done by the authors named in this article and all liabilities pertaining to claims relating to the content of this article will be borne by the authors. Hu Cai designed all the experiments and revised the paper. Liyan Gong, Qinfei Zhou and Xiangming Kong performed the experiments, and Liyan Gong wrote the paper.

\section{REFERENCES}

1. Clohisy DR, Mantyh PW. Bone cancer pain. Cancer 2003; 97: 866

2. Coleman RE. Skeletal complications of malignancy. Cancer 1997; 80: 1588-1594.

3. Coleman RE. Clinical features of metastatic bone disease and risk of skeletal morbidity. Clin Cancer Res 2006; 12 $6243 s$

4. Yang $Y$, Li H, Li TT, Luo H, Gu XY, Lü N, Ji RR, Zhang $Y Q$. Delayed activation of spinal microglia contributes to the maintenance of bone cancer pain in female Wistar rats via P2X7 receptor and IL-18. J Neurosci 2015; 35: 7950-7963.

5. Meuser T, Pietruck $C$, Radbruch L, Stute $P$, Lehmann $K A$, Grond S. Symptoms during cancer pain treatment following WHO-guidelines: a longitudinal follow-up study of symptom prevalence, severity and etiology. Pain 2001; 93: 247

6. Li QQ, Wang G, Huang $F$, Banda $M$, Reed $E$. Antineoplastic effect of beta-elemene on prostate cancer cells and other types of solid tumour cells. J Pharm Pharmacol 2010; 62: 1018-1027.

7. Zhao SY, Wu J, Fang $Z$, Tang $Q$, Yang LJ, Li L, Wu WY, Hann SS. $\beta$-elemene inhibited expression of DNA methyltransferase 1 through activation of ERK1/2 and AMPKa signalling pathways in human lung cancer cells: the role of Sp1. J Cell Mol Med 2015; 19: 630-641.

8. Guan $C$, Liu $W$, Yue $Y$, Jin $H$, Wang $X$, Wang $X J$. Inhibitory effect of $\beta$-elemene on human breast cancer cells. Int J Clin Exp Pathol 2014; 7: 3948-3956.

9. Li QQ, Wang G, Liang H, Li JM, Huang F, Agarwal PK, Zhong Y, Reed E. $\beta$-Elemene promotes cisplatin-induced cell death in human bladder cancer and other carcinomas. Anticancer Res 2013; 33: 1421.

10. Chen G, Xie RG, Gao YJ, Xu ZZ, Zhao LX, Bang S, Berta $T$, Park CK, Lay $M$, Chen $W$. $\beta$-arrestin-2 regulates NMDA receptor function in spinal lamina II neurons and duration of persistent pain. Nat Commun 2016; 7: 12531.

11. Tabakoff $B$, Ren $W$, Vanderlinden $L$, Snell $L D$, Matheson CJ, Wang ZJ, Levinson R, Smothers CT, Woodward JJ,
Honse Y. A novel substituted aminoquinoline selectively targets voltage-sensitive sodium channel isoforms and NMDA receptor subtypes and alleviates chronic inflammatory and neuropathic pain. Eur $J$ Pharmacol 2016; 784: 1-14

12. Yang JX, Hua $L$, Li YQ, Jiang $Y Y$, Han D, Liu H, Tang $Q Q$, Yang $X N$, Yin C, Hao LY et al.. Caveolin-1 in the anterior cingulate cortex modulates chronic neuropathic pain via regulation of $N M D A$ receptor $2 B$ subunit. $J$ Neurosci 2015; 35: 36

13. Hanamura K, Washburn HR, Shefflercollins SI, Xia NL, Henderson N, Tillu DV, Hassler S, Spellman DS, Zhang G, Neubert TA. Extracellular phosphorylation of a receptor tyrosine kinase controls synaptic localization of NMDA receptors and regulates pathological pain. PLoS Biol 2017; 15: e2002457.

14. Swartjes M, Morariu A, Niesters M, Aarts L, Dahan A. Nonselective and $N R 2 B$-selective $N$-methyl-D-aspartic acid receptor antagonists produce antinociception and long-term relief of allodynia in acute and neuropathic pain. Anesthesiology 2011; 115: 165.

15. Sun $Y$, Jiang $M$, Hou B, Lu C, Lei $Y$, Ma Z, Gu X. MasRelated Gene (Mrg) C Activation Attenuates Bone Cancer Pain via Modulating Gi and NR2B. PLOS ONE 2016; 11: e0154851.

16. Bu F, Tian $H$, Gong $S$, Zhu $Q, X u$ GY, Tao J, Jiang $X$. Phosphorylation of NR2B NMDA subunits by protein kinase $C$ in arcuate nucleus contributes to inflammatory pain in rats. Sci Rep 2015; 5.

17. Kamiya $Y$, Saeki K, Takiguchi M, Funakoshi K. CDK5, CRMP2 and NR2B in spinal dorsal horn and dorsal root ganglion have different role in pain signaling between neuropathic pain model and inflammatory pain model. Eur J Anaesth 2013; 30: 214-214.

18. Zimmermann M. Ethical guidelines for investigations of experimental pain in conscious animals. Pain 1983; 16: 109.

19. Schwei MJ, Honore $P$, Rogers SD, Salakjohnson JL, Finke MP, Ramnaraine ML, Clohisy DR, Mantyh PW. Neurochemical and cellular reorganization of the spinal cord in a murine model of bone cancer pain. J Neurosci 1999; 19: 10886-10897.

20. Gu XP, Zhang J, Ma ZL, Wang JH, Zhou XF, Jin YQ, Xia $X P$, Gao $Q$, Mei FM. The role of $N$-methyl- $d$-aspartate receptor subunit $N R 2 B$ in spinal cord in cancer pain. Eur J Pain 2010; 14: 496-502.

21. Wang S, Cheng G, Joshua C, He Z, Sun X, Li R, Liu L, Yuan $Q$. Furfural tolerance and detoxification mechanism in Candida tropicalis. Biotechnol Biofuels 2016; 9: 250

22. Woolf CJ, Salter MW. Neuronal plasticity: increasing the gain in pain. Science 2000; 288: 1765.

23. Ni K, Zhou Y, Sun YE, Liu Y, Gu XP, Ma ZL. Intrathecal injection of selected peptide Myr-RC-13 attenuates bone cancer pain by inhibiting KIF17 and NR2B expression. Pharmacol Biochem Be 2014; 122: 228.

24. Lau CG, Takeuchi K, Rodenas-Ruano A, Takayasu Y, Murphy J, Bennett MV, Zukin RS. Regulation of NMDA 
receptor Ca2+ signalling and synaptic plasticity. Biochem Soc Trans 2009; 37: 1369-1374.

25. Gu X, Zhang J, Ma Z, Wang J, Zhou X, Jin Y, Xia X, Gao $Q$, Mei $F$. The role of $N$-methyl-D-aspartate receptor subunit NR2B in spinal cord in cancer pain. Eur J Pain 2010; 14: 496-502.

26. Tan PH, Yang LC, Shih HC, Lan KC, Cheng JT. Gene knockdown with intrathecal siRNA of NMDA receptor
NR2B subunit reduces formalin-induced nociception in the rat. Gene Ther 2005; 12: 59-66.

27. Qu XX, Cai J, Li MJ, Chi YN, Liao FF, Liu FY, Wan Y, Han JS, Xing GG. Role of the spinal cord NR2Bcontaining NMDA receptors in the development of neuropathic pain. Exp Neurol 2009; 215: 298-307. 